\title{
Health through martial arts training: Physical fitness and reaction time in adolescent Taekwondo practitioners
}

\author{
Shirley S. M. Fong ${ }^{1 \#}$, Shamay S. M. Ng$^{2}$, Louisa M. Y. Chung ${ }^{3}$ \\ ${ }^{1}$ Institute of Human Performance, The University of Hong Kong, Hong Kong, China; \\ \#Corresponding Author: smfong@hku.hk, smfong_2004@yahoo.com.hk \\ ${ }^{2}$ Department of Rehabilitation Sciences, The Hong Kong Polytechnic University, Hong Kong, China \\ ${ }^{3}$ Department of Health and Physical Education, The Hong Kong Institute of Education, Hong Kong, China
}

Received 17 April 2013; revised 17 May 2013; accepted 1 June 2013

Copyright (C) 2013 Shirley S. M. Fong et al. This is an open access article distributed under the Creative Commons Attribution License, which permits unrestricted use, distribution, and reproduction in any medium, provided the original work is properly cited.

\begin{abstract}
Taekwondo (TKD) is a popular sport among adolescents, but the potential benefits of TKD training to young individuals are not well understood. The objectives of this cross-sectional exploratory study were to compare flexibility, muscular endurance, body composition, and simple reaction time between TKD-trained adolescents and controls. Twenty TKD-trained adolescents aged between 10 and 14 and 20 age-matched healthy controls were asked to perform five physical fitness tests: a sit-and-reach test, leg split test, skinfold measurement, one-minute curl-up test, and ruler-drop reaction time test. The results revealed no significance differences between the two groups in sit-and-reach distance $(p=0.690)$, leg split angle $(p=0.789)$, percentage of body fat $(p=0.342)$, or number of repetitions in the one-minute curl-up test $(p=0.250)$. However, the TKD group had significantly faster reaction times in the ruler-drop test than the control group $(p=0.005)$. The results thus suggest that although TKD training may improve reaction times in adolescents, it may have little effect on flexibility, muscular endurance, and body composition (percentage of fat). TKD may be a suitable exercise for improving simple reaction time, but it may not be suitable for improving general physical fitness in adolescents.
\end{abstract}

Keywords: Martial Arts; Sports; Health;

Adolescence

"Conflicts of interest: The authors declare that they have no conflicts of interest with respect to the authorship or publication of this paper. No funding was provided for its preparation.

\section{INTRODUCTION}

Inactivity or suboptimal levels of physical activity is associated with adverse health consequences in adolescents, such as obesity $[1,2]$. It has also been reported that active teens are less likely to engage in risky behavior (e.g., cigarette smoking and alcohol intake), enjoy higher self-esteem [1], suffer fewer chronic diseases, are more physically fit, and have better bone health [2]. These potential beneficial effects of physical activity may persist into adulthood [2]. Physical activity, including participation in sports, is thus of paramount importance in young people.

Taekwondo (TKD) is a form of martial arts that originnated in Korea, and has gained popularity among young people internationally. More than 80 million people worldwide currently practice TKD [3-5], but the potential physical benefits of TKD training in adolescents remain unclear. A review of the existing evidence shows that TKD training may be associated with a reduction in fat and improvements in flexibility [6] and reaction time [7], but seems not to improve muscular strength [6]. More studies are needed to establish the efficacy of such training in improving health-related physical fitness in young individuals. The aim of this study was thus to compare flexibility, muscular endurance, body fat percentage, and simple reaction time in TKD-trained adolescents and age-matched healthy controls. Its findings may inspire the use of TKD in improving health and fitness in adolescents.

\section{METHODS}

\subsection{Participants}

Twenty young TKD practitioners were recruited from a TKD association by convenience sampling. The inclu- 
sion criteria were: 1) aged between 10 and 14 years old and 2) involvement in regular TKD training (for at least 90 minutes per week) for more than three consecutive months. The exclusion criteria were: 1) a significant musculoskeletal, neurological, cardiopulmonary, or genetic disorder and 2) regular, intense participation in sports activities other than TKD. Another 20 healthy age-matched adolescents were recruited from the local community as controls. The latter had to fulfill all of the aforementioned inclusion and exclusion criteria except for regular TKD training.

This study was approved by the Human Subjects Ethics Review Subcommittee of the Hong Kong Polytechnic University, and followed the guidelines of the Declaration of Helsinki. Written informed consent was obtained from both the participants and their parents. All of the assessments were conducted by four physiotherapy students. After a short warm-up period, the participants performed the following tests in random order.

\subsection{Sit-and-Reach Test}

The sit-and-reach test was used to assess participants' lower back and hamstring flexibility [8] because such flexibility is essential to execute the high kicks required by TKD [9]. During this test, the participants sat barefoot in the long sitting position with the soles of their feet pressed flat against the sit-and-reach box. They were instructed to slowly reach forward (with both hands in parallel) as far as possible with their knees in full extension. The bilateral fingertips of their middle fingers had to overlap and remain in contact with the measurement portion of the sit-and-reach box. The most distant point (in centimeters) reached with the fingertips was recorded. The participants performed three trials, and their best score was used for analysis [8].

\subsection{Leg-Split Test}

Because flexibility is joint-specific and TKD training involves many kicking movements (e.g., side kick and roundhouse kick) that require flexibility of the hip adductor muscles [9], participants' hip abduction passive range of motion (ROM) was measured. They lay supine on a mat with their pelvis kept level. The assessor then slowly moved the tested femur (hip joint) to the limit of hip abduction with the knee in extension. Participants' maximum passive hip abduction ROM was measured with a universal goniometer [10]. Each hip was assessed three times, with the average hip abduction ROM recorded. The average hip abduction ROM values of both hips were added together to represent the combined legsplit angle, which was used for further analysis.

\subsection{One-Minute Curl-Up Test}

The one-minute curl-up test is a commonly used field assessment for muscular endurance. The participants assumed a crook-lying position on a mat with their knees flexed at $90^{\circ}$ and their arms lying by the side of their trunk. They were then instructed to perform as many curl-ups as possible (i.e., to lift their scapulae off the mat, with their trunk forming a $30^{\circ}$ angle with the mat) in one minute [8]. The number of curl-up repetitions performed represented participants' abdominal muscle endurance, and was used for analysis.

\subsection{Skinfold Measurements}

The total amount of body fat was estimated using skinfold measurements. According to the guidelines of the American College of Sports Medicine (ACSM) [8], the skinfold thicknesses of three body parts (for males: right chest, abdomen, and thigh; for females: the right triceps, suprailiac and thigh) were measured using a skinfold caliper. The sum of the three measurements was converted to body density and then to the percentage of body fat using regression equations. Table 1 presents the measurement sites and the regression equations used to estimate body fat in the male and female participants. The body fat percentages of both groups of participants were used for analysis.

\subsection{Ruler-Drop Reaction Time Test}

Simple reaction time was estimated by asking the participants to catch a falling ruler. They were invited to sit on a chair with their dominant hand kept in the midprone position, elbow flexed to $90^{\circ}$, and forearm supported on a table. The assessor held the ruler vertically, with its lower end between the participant's thumb and index finger (i.e., web space). He or she was then instructed to catch the ruler using a pinch grasp as quickly as possible when the assessor released it at an unannounced time. The reaction time (in seconds) of each participant was calculated with the following equation.

Table 1. Skinfold measurement and calculation of body fat percentage in Asian populations according to ACSM guidelines [8].

\begin{tabular}{|c|c|c|}
\hline & Male & Female \\
\hline $\begin{array}{l}\text { Sites of } \\
\text { measurement }\end{array}$ & $\begin{array}{l}\text { Chest, abdomen, } \\
\text { and thigh }\end{array}$ & $\begin{array}{l}\text { Triceps, suprailiac, } \\
\text { and thigh }\end{array}$ \\
\hline $\begin{array}{l}\text { Body density } \\
\text { formula }\end{array}$ & $\begin{array}{c}1.10938- \\
0.0008267 \text { (sum of } \\
3 \text { skinfolds) }+ \\
0.0000016 \text { (sum of } \\
3 \text { skinfolds) })^{2}- \\
0.0002574 \text { (age) }\end{array}$ & $\begin{array}{c}1.099421- \\
0.0009929 \text { (sum of } \\
3 \text { skinfolds) }+ \\
0.0000023 \text { (sum of } \\
3 \text { skinfolds) })^{2}- \\
0.0001392 \text { (age) }\end{array}$ \\
\hline $\begin{array}{l}\text { Percentage of body } \\
\text { fat formula } \\
\text { (Asian-specific) }\end{array}$ & $\begin{array}{c}4.97 /(\text { body density) } \\
-4.52\end{array}$ & $\begin{array}{c}4.76 / \text { (body density) } \\
-4.28\end{array}$ \\
\hline
\end{tabular}




$$
\text { Reaction time }=\sqrt{2 \cdot \text { distance } / 9.18}
$$

Distance $(\mathrm{m})$ was calculated by the difference between the initial and final grasping height of the ruler, and 9.81 $\left(\mathrm{ms}^{-2}\right)$ represents the gravity constant [11]. A familiarizetion trial was carried out before the actual test. Three testing trials were then performed, with the average reaction time recorded for analysis.

\subsection{Statistical Analysis}

SPSS 20.0 was used for data analysis. Descriptive statistics were used to describe all of the demographic and outcome variables. The Kolmogorov-Smirnov test was first performed to check the normality of the data. An independent t-test was then performed to compare the age, height, and weight of the TKD and control group participants, and a chi-square test to compare the two groups by the categorical demographic variable (i.e., sex). Finally, to compare the physical fitness performance of the TKD and control groups while accounting for the confounding effect of sex, single multivariate analysis of covariance (MANCOVA) incorporating all of the outcome variables (i.e., leg split angle, sit-and-reach distance, number of repetitions in the one-minute curl-up test, percentage of body fat, and reaction time) was performed, with subject group as the fixed factor and sex as the covariate. Effect sizes (partial eta-squared) and Bonferroni-adjusted $\mathrm{p}$ values were calculated. Alpha was set at 0.05 for all of the statistical tests (two-tailed).

\section{RESULTS}

No significant differences were found between the TKD and control groups in age, body height, or weight, although there was a significant difference in the maleto-female ratio (Table 2). Therefore, sex was treated as a covariate in the subsequent statistical analysis. MANCOVA revealed a significant difference in overall physiccal fitness performance between the two groups (Hotelling's Trace $=3.056, \mathrm{p}=0.023$ ). When each individual outcome was considered, however, no significant between-group differences were found in the leg split ang-

Table 2. Demographic data of participants.

\begin{tabular}{lccc}
\hline & $\begin{array}{c}\text { TKD group } \\
(\mathrm{n}=20)\end{array}$ & $\begin{array}{c}\text { Control group } \\
(\mathrm{n}=20)\end{array}$ & p value \\
\hline Age, year & $11.3 \pm 1.3$ & $11.4 \pm 1.2$ & 0.899 \\
Height, $\mathrm{m}$ & $1.5 \pm 0.1$ & $1.5 \pm 0.1$ & 0.535 \\
Weight, $\mathrm{kg}$ & $43.3 \pm 9.7$ & $41.5 \pm 13.1$ & 0.634 \\
Sex (male/female), $\mathrm{n}$ & $19 / 1$ & $10 / 10$ & $0.003^{*}$ \\
TKD experience, year & $2.8 \pm 1.8$ & 0 & \\
\hline
\end{tabular}

Values are mean $\pm \mathrm{SD} .{ }^{*} \mathrm{p}<0.05$. le, sit-and-reach distance, number of repetitions in the one-minute curl-up test, or the percentage of body fat. The only significant such difference was in reaction time, with that of the TKD-trained participants found to be significantly faster than that of the controls $(13.6 \%, \mathrm{p}=$ 0.005). Among the outcome variables that showed nonsignificant between-group differences, the effect sizes ranged from 0.002 to 0.037 , which are small effect sizes [12] (Table 3).

\section{DISCUSSION}

To the best of our knowledge, this is the first study to investigate reaction time in typically developing adolescents taking part in regular TKD training. The participating TKD-trained teenagers had a faster simple reaction time in the ruler-drop test than their untrained counterparts. This finding is in line with previous studies showing a faster reaction time in mentally retarded youths after TKD training [13] and in TKD-trained adults [7]. Because reaction time can be divided into premotor reaction time (i.e., the latency between stimulus onset and muscle contraction onset) and movement time [13], we are unsure whether our TKD participants had a shorter premotor reaction time and/or movement time. Although a previous study showed that mature martial arts practitioners have a faster movement time but not a faster premotor reaction time [7], further study is needed to explore whether the same would apply to developing individuals.

In contrast to earlier studies $[6,14,15]$, hamstring and hip adductor muscle flexibility was no higher in the TKD-trained adolescents than in the controls in this study. The difference may be due to the large between-group discrepancy in the male-to-female ratio in our study, despite sex being treated as a covariate in the statistical analysis. As females are generally superior to males in terms of flexibility [16], our TKD group (5\% females) should have displayed less flexibility than the control

Table 3. Comparison of outcome variables between TKD and control groups.

\begin{tabular}{lcccc}
\hline & $\begin{array}{c}\text { TKD group } \\
(\mathrm{n}=20)\end{array}$ & $\begin{array}{c}\text { Control group } \\
(\mathrm{n}=20)\end{array}$ & $\mathrm{p}$ value & $\begin{array}{c}\text { Effect } \\
\text { size }\end{array}$ \\
\hline $\begin{array}{l}\text { Leg split angle } \\
\left(^{\circ}\right)\end{array}$ & $107.90 \pm 24.80$ & $113.68 \pm 12.92$ & 0.789 & 0.002 \\
$\begin{array}{l}\text { Sit-and-reach } \\
(\mathrm{cm})\end{array}$ & $24.96 \pm 10.24$ & $26.39 \pm 10.58$ & 0.690 & 0.004 \\
$\begin{array}{l}\text { One-minute } \\
\text { curl-up } \\
\text { (repetitions) }\end{array}$ & $33.20 \pm 7.95$ & $33.89 \pm 8.47$ & 0.250 & 0.037 \\
$\begin{array}{l}\text { Body fat }(\%) \\
\begin{array}{l}\text { Reaction time } \\
(\mathrm{s})\end{array}\end{array}$ & $13.61 \pm 7.21$ & $17.16 \pm 9.65$ & 0.342 & 0.025 \\
\hline
\end{tabular}

Values are mean $\pm \mathrm{SD} .{ }^{*} \mathrm{p}<0.05$. 
group (50\% females), but in fact the two groups displays a similar level of flexibility. The implication is that TKD training may have improved the flexibility of the largely male TKD group, although further prospective study is necessary to confirm this potentially beneficial effect.

It is known that trunk (core) muscle strength and endurance are essential for sports performance [17] and injury prevention [18] in athletes. Therefore, we hypothesized that TKD-trained adolescents would display greater muscular endurance in their abdominal muscles relative to controls. However, our results revealed that the two groups performed a similar number of curl-ups in one minute. Previous studies have also reported muscular endurance, as measured by the one-minute sit-up (curlup) test, to be no greater in TKD athletes [7,19]. It is possible that muscle training in TKD focuses on the lower limbs $[20,21]$ rather than the trunk. As strong trunk muscles are essential for sports performance and injury prevention [17,18], TKD coaches should consider including more trunk musculature-strengthening activities and techniques during training.

We found no significant differences in the percentage of body fat between the TKD practitioners and nonpractitioners. Previous studies have reported lower adiposity in advanced male and female TKD practitioners who have attained the black-belt level [22] and in elite TKD athletes [23]. These findings do not contradict ours, as our participants were recreational TKD practitioners with an average of only 2.8 years of training experience. None had yet attained the black-belt level. We thus postulate that the insignificant between-group difference was the result of participants' inadequate training period and the low degrees of intensity and frequency of that training [8].

The major limitation of this study was its cross-sectional research design. We cannot be sure whether the observed difference (in reaction time) was the result of nature (e.g., genetics) or nurture (e.g., TKD training). Further prospective randomized controlled trials may be necessary to confirm the beneficial effects of TKD training in adolescents. Moreover, the effect of sex should also be taken into account when analyzing physical fitness variables. Researchers may consider using a larger sample and analyzing the data on males and females separately.

\section{CONCLUSION}

Adolescent TKD practitioners demonstrate a faster simple reaction time than their untrained counterparts, although the two groups have similar levels of flexibility, muscular endurance, and body fat. TKD may thus be a suitable exercise for improving simple reaction time in adolescents, but may not be appropriate for improving general physical fitness in this population.

\section{ACKNOWLEDGEMENTS}

The authors would like to thank Mr. Keison K. S. Tam, Mr. S. P. Chau, Miss Rachael W. S. Ngan and Mr. H. C. Cheung for recruiting participants and collecting data.

\section{REFERENCES}

[1] Nelson, M.C. and Gordon-Larsen, P. (2006) Physical activity and sedentary behavior patterns are associated with selected adolescent health risk behaviors. Pediatrics, 117, 1281-1290. doi:10.1542/peds.2005-1692

[2] Hallal, P.C., Victora, C.G., Azevedo, M.R. and Wells, J.C.K. (2006) Adolescent physical activity and health. Sports Medicine, 36, 1019-1030. doi:10.2165/00007256-200636120-00003

[3] Park, Y.H., Park, Y.H. and Gerrard, J. (1989) Tae Kwon Do: The Ultimate Reference Guide to the World's Most Popular Martial Art. Ward Lock, London.

[4] ITF (1994) ITF tournament rules. http://www.itf-information.com/information10c.htm

[5] WTF. (2009) WTF rules and regulations. http://www.wtf.org/wtf_eng/site/rules/file/20090203_Rul es and Regulations of the WTF as of February $3 \quad 20$ 09.pdf

[6] Fong, S.S.M. and Ng, G.Y.F. (2011) Does Taekwondo training improve physical fitness? Physical Therapy in Sport, 12, 100-106. doi:10.1016/j.ptsp.2010.07.001

[7] O'Donovan, O., Cheung, J., Catley, M., McGregor, A.H. and Strutton, P.H. (2006) An investigation of leg and trunk strength and reaction times of hard-style martial arts practitioners. Journal of Sports Science and Medicine, 5, 5-12.

[8] ACSM (American College of Sports Medicine). (2006) ACSM's Guidelines for Exercise Testing and Prescription. 7th Edition, Lippincott Williams \& Wilkins, Philadelphia.

[9] Pieter, W. and Heijmans, J. (2000) Scientific Coaching for Olympic Taekwondo. 2nd Edition, Meyer and Meyer Sport, Aachen.

[10] Clarkson, H.M. (2000) Musculoskeletal assessmentJoint range of motion and manual muscle strength. 2nd Edition, Lippincott Williams \& Wilkins, Philadelphia.

[11] Carmeli, E., Bar-Yossef, T., Ariav, C., Levy, R. and Liebermann, D.G. (2008) Perceptual-motor coordination in persons with mild intellectual disability. Disability and Rehabilitation, 30, 323-329. doi:10.1080/09638280701265398

[12] Portney, L.G. and Watkins, M.P. (2009) Foundations of Clinical Research-Applications to Practice. 3rd Edition, Pearson Education Inc., Upper Saddle River.

[13] Song, K.Y. and An, J.D. (2004) Premotor and motor reaction time of educable mentally retarded youths in a Taekwondo program. Perceptual and Motor Skills, 99, 711723. doi:10.2466/pms.99.2.711-723

[14] Kim, H.B., Stebbins, C.L., Chai, J.H. and Song, J.K. (2011) Taekwondo training and fitness in female adolescents. Journal of Sports Sciences, 29, 133-138. 
doi:10.1080/02640414.2010.525519

[15] Toskovic, N.N., Blessing, D. and Williford, H.N. (2004) Physiologic profile of recreational male and female novice and experienced Tae Kwon Do practitioners. Journal of Sports Medicine and Physical Fitness, 44, 164-172.

[16] Bale, P., Mayhew, J.L., Piper, F.C., Ball, T.E. and Willman, M.K. (1992) Biological and performance variables in relation to age in male and female adolescent athletes. Journal of Sports Medicine and Physical Fitness, 32, 142-148.

[17] Hibbs, A.E., Thompson, K.G., French, D., Wrigley, A. and Spears, I. (2008) Optimizing performance by improving core stability and core strength. Sports Medicine, 38, 9951008.doi:10.2165/00007256-200838120-00004

[18] Leetun, D.T., Ireland, M.L., Willson, J.D., Ballantyne, B.T. and Davis, I.M. (2004) Core stability measures as risk factors for lower extremity injury in athletes. Medicine \& Science in Sports \& Exercise, 36, 926-934. doi:10.1249/01.MSS.0000128145.75199.C3

[19] Noorul, H.R., Pieter, W. and Erie, Z.Z. (2008) Physical fitness of recreational adolescent Taekwondo athletes.
Brazilian Journal of Biomotricity, 2, 230-240.

[20] Fong, S.S.M. and Tsang, W.W.N. (2012) Relationship between the duration of Taekwondo training and lower limb muscle strength in adolescents. Hong Kong Physiotherapy Journal, 30, 25-28. doi:10.1016/j.hkpj.2011.11.004

[21] Fong, S.S.M., Chung, J.W.Y., Chow, L.P.Y., Ma, A.W.W. and Tsang, W.W.N. (2013) Differential effect of Taekwondo training on knee muscle strength and reactive and static balance control in children with developmental coordination disorder: A randomized controlled trial. Research in Developmental Disabilities, 34, 1446-1455. doi:10.1016/j.ridd.2013.01.025

[22] Heller, J., Peric, T., Dlouha, R., Kohlikova, E., Melichna, J. and Novakova, H. (1998) Physiological profiles of male and female Taekwon-do (ITF) black belts. Journal of Sports Sciences, 16, 243-249. doi: $10.1080 / 026404198366768$

[23] Fritzche, J. and Raschka, C. (2008) Body composition and the somatotype of German top Taekwondo practitioners. Papers on Anthropology, 17, 58-71. 